\title{
Fistula from left main coronary artery to pulmonary trunk
}

\author{
N. Papakonstantinou - N. Miaris - K. Argyrakis - S. Mitsiadis - A. Dimopoulos - G. Gavrielatos - N. Patsourakos · \\ N. Kasinos · A. Theodosis-Georgilas · E. Pisimisis
}

Published online: 10 March 2020

(c) The Author(s) 2020

\section{Answer}

The invasive coronary angiography showed a fistula originating from the left main coronary artery and no other haemodynamically significant coronary arterial lesions. Although the old age of our patient could discourage any further investigation (81-year-old patient with most probably a lifetime coronary fistula), computed tomography coronary angiography (CTCA) was performed and revealed this fistula draining into the main pulmonary artery (Fig. 1). Single-photon emission computed tomography with technetium$99 \mathrm{~m}$ sestamibi showed permanent myocardial perfusion deficits with no stress ischaemic disturbances. Optimal medical treatment was adopted with good patient's response.

Coronary-to-pulmonary artery fistulas are rare coronary connections (literature rates of $<0.7 \%$ ) most frequently originating from the left main coronary artery, the left anterior descending artery or the right coronary artery and draining into the main pulmonary artery [1]. Although they are often incidental findings (CTCA has increased diagnosis rates), patients may present with angina, dyspnoea, congestive heart failure, pulmonary hypertension, arrhythmias and sudden cardiac death. Therefore, their possible clinical effects need further investigation in order to adopt either interventional (surgery/transcatheter closure) or conservative treatment, avoiding any com-

\footnotetext{
N. Papakonstantinou · N. Miaris $(\varangle) \cdot \mathrm{K}$. Argyrakis ·

S. Mitsiadis · A. Dimopoulos · G. Gavrielatos ·

N. Patsourakos · N. Kasinos · A. Theodosis-Georgilas ·

E. Pisimisis

Cardiology Department, “Tzaneio” General Hospital of

Piraeus, 18536 Piraeus, Greece

nmiaris@gmail.com
}

plications such as aneurysm creation, vessel dissection, pericardial effusion, coronary arterial steal phenomenon, thrombosis and myocardial infarction [1-3].

Conflict of interest N. Papakonstantinou, N. Miaris, K. Argyrakis, S. Mitsiadis, A. Dimopoulos, G. Gavrielatos, N. Patsourakos, N. Kasinos, A. Theodosis-Georgilas and E. Pisimisis declare that they have no competing interests.

Open Access This article is licensed under a Creative Commons Attribution 4.0 International License, which permits use, sharing, adaptation, distribution and reproduction in any medium or format, as long as you give appropriate credit to the original author(s) and the source, provide a link to the Creative Commons licence, and indicate if changes were made. The images or other third party material in this article are included in the article's Creative Commons licence, unless indicated otherwise in a credit line to the material. If material is not included in the article's Creative Commons licence and your intended use is not permitted by statutory regulation or exceeds the permitted use, you will need to obtain permission directly from the copyright holder. To view a copy of this licence, visit http://creativecommons.org/licenses/by/4.0/.

\section{References}

1. Verdini D, Vargas D, Kuo A, et al. Coronary-pulmonary artery fistulas: a systematic review. J Thorac Imaging. 2016;31:380-90.

2. Vaidya Y, Green G. Coronary artery fistula. J Card Surg. 2019;34(12):1608-1616.

3. Strecker T, Nooh E, Weyand M, Agaimy A. Huge coronary artery fistula to the pulmonary artery. J Card Surg. 2019;34:350-1. 


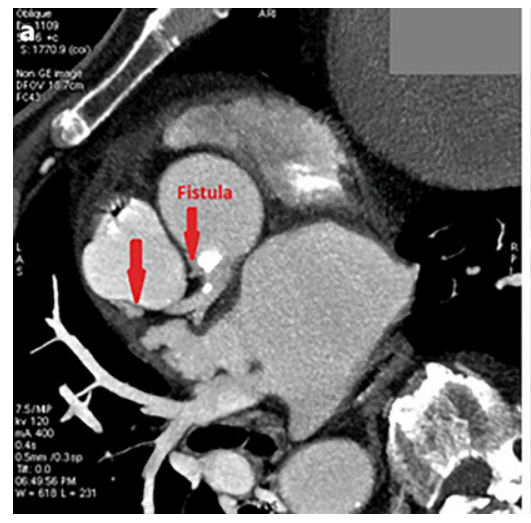

Fig. 1 a and $\mathbf{b}$ Computed tomography coronary angiography views; c Three-dimensional reconstruction. A fistula arising from the left main coronary artery and draining into the
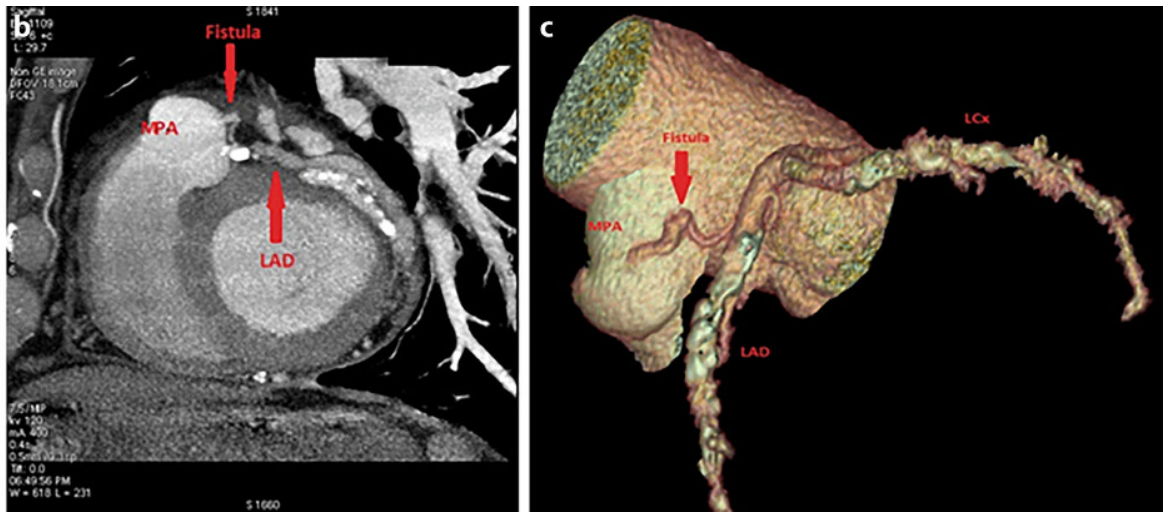

main pulmonary artery is depicted. $L A D$ left anterior descending artery, $L C x$ left circumflex artery, $L M C A$ left main coronary artery, MPA main pulmonary artery 